\title{
UNDERSTANDING THE ENGAGEMENT PATTERNS OF SENIOR CITIZENS WITH SMARTPHONE: A CASE STUDY OF ISLAMABAD PAKISTAN
}

\author{
Obaid \\ Ph.D. Scholar \\ Department of Sociology, Quaid-i-Azam University Islamabad \\ Email: obaidkhan2011@ hotmail.com \\ Farhan Ahmad Faiz \\ Assistant Professor Department of Sociology Quaid-i-Azam University Islamabad \\ Email: farhanfaiz@qau.edu.pk \\ Farrah Ahmed \\ Ph.D. scholar International Islamic University Islamabad. \\ Email: farrahahmed28@gmail.com
}

\begin{abstract}
Aging is a universal phenomenon and every society has senior citizens at the age of 50 years and above, while the usage of smartphone at this age varies from society to society and individual to individual. However, the trend of using smartphone in senior citizens is increasing day by day across the globe and Pakistan is no exception to it. This study aims to explore the ways of engagement with smartphone and its facilitation provided to senior citizens. The qualitative technique was used in which in-depth interviews were conducted to collect data about demographic, practices, benefits, motives and barriers of using smartphone. Fifteen participants, aged 50 years and above, having the smartphones were interviewed using a semi-structured interview method. The interviews were conducted in Islamabad Pakistan. The results revealed that senior citizens are engaged with their smartphones for different purposes such as calls, messages, social media such as Facebook, WhatsApp, and YouTube etc. The data also shows that the senior citizens have been benefited in terms of social connectedness, information, entertainment, mobility, and online booking of different activities. Furthermore, the result also indicates some difficulties in using smartphone which are due to lack of IT literacy and weak eye sight.
\end{abstract}

Keywords: Senior Citizen, Engagement patterns, Smartphone.

\section{INTRODUCTION}

Studies show that there is a lack of consensus on the matter of defining old age. For instance, Laslett (1995) stated that the classification of old age is based on the personal perception of individuals. He also mentioned that the cultural and societal norms also affect this classification. This is a constructivist's view. The common definition of old is still the chronological which means the age measured in years lived (Tongre, 1988). The U.S. Social Security Act of 1935 still leading this way. This act was viewed as "old-age security legislation" intended for people age 65 and older (Graebner, 1980). Consequently, "the prevailing pension age became, in popular as well as official discourse, the boundary between middle and old age" (Thane, 2005). As a result, most developed world countries have accepted the chronological age of 65 years as a definition of "elderly" or older person (World Health Organization, 2007).

In a report of United Nations (2002), the population of elderly people in Asia was roughly 57.6 million making 4.1 percent of the total population in 1950. Due to the rapid growth in the life expectancy, the population of elderly people may be expected to reach 922.7 million making 17.5 percent in the mid of this century. In 1950, Asia had 44 percent of the global elderly population, but by 2050, it will increase to 62 percent. Between 1950 and 1975, the number of old citizens increased to 70 percent from 57.6 million to 97.7 million. By 2005, the Asia's demographic background had become totally different. The portion of old citizens, the middle aged, and the elderly citizens' dependency ratio were on the rise, while 
that of the younger population was stagnant. Predictions indicate that this trend is irretrievable, as shared before that by 2050, the population of older citizens would reach 922.7 million making 17.5 percent of the total population. The middle aged will grow to 40.2 years and the dependency proportion of the elderly people will rise to 38.8 (UN, 2002). According to World Health Organization (WHO) report in 1998, the life expectancy in Pakistan has risen by three decades in last fifty years and will reach close over 72 years by 2023. So the estimated ratio of people over 60 years is $6 \%$ in Pakistan with a likelihood of doubling by 2025 (International data base, 2004). The point to be made here is to find out the influence of technology on the changes in pattern of elderly peoples' life expectancy.

Technology and society established links in the arena of science and technological studies. To understand technology in society, it is better to combine social science with technology and to use integrated methods for studying aging and technology. This combine approach can give the base for upcoming changes in technology and a "good life" for older citizen. In the analysis of technological advancements as a social process, the question arises that which technologies are developed, who considered them developed for whom and under what conditions (Hackett et al., 2007). Studying the wider field of "ageing and technology" can shape up the investigation of the advancement of a specific technology and its broader perspective in which it takes place. For example, the investigation of discourses which support particular funding policies and judgments by public sector, corporate to finance in the advancement of particular products, like neoliberal dissertation on individual's self-responsibility joint with the advertisement of lively ageing (van Dyk, 2009).

With the passage of time, technology has advanced manifolds especially innovations in smartphones. Many studies show that the dependency ratio of mobile phones in elderly people is increasing due to human development and consequently risk of isolation. Furthermore, their mobility and interaction with friends, families and neighbors may become limited. Technology in particular smart phones provide engagement with other individuals, communication and entertainment. Through smart phones, the elderly people improve their independence in daily routine activities and cognitive skills. As a result, it commonly creates an additional layer of communication (Fernández-Ardèvol \& Arroyo, 2012). Furthermore, smart phones enable elderly people to get different kinds of services (online banking, Money transfer, appointments, Uber, Careem). From these studies a gap is identified, which needs exploration that what are the ways of engagements of senior citizens with smart phones? And what are the facilitations that smart phones provide to senior citizens in Pakistan?

As the case of Pakistan is concerned, the elderly population is $10.5 \%$ of the total population as per census of 2017, and their dependency ratio is $7.4 \%$ which will be doubled probably by 2025 (UNO, 2002, p. 61). Ageing in Pakistan is one of the burning issues which needs policy initiatives and research to tackle. The elderly population in Pakistan is the marginalized area in the field of research especially their relationship with technology specifically with smart phones. In Pakistan, the elderly people face a lot of barriers in the way of utilizing technology especially smartphones. Their usage/non-usage, motives, practices and interest in using smart phones need to be studied. The current study is an effort to answer the research questions that, what are the ways of engagements of senior citizens with smart phones and what are the facilitations provided by smart phones to senior citizens? It will focus on the user, the practices of user and will also explore the types of involvement elderly people have with mobiles phones.

\section{REVIEW OF LITERATURE}

Technology and society were established in the arena of science and technological studies, as the science developed, technological advancements were made and so the societies started interacting. Downey (2001) mentioned in his study of anthropology of science and technology that society and technology are strongly inter-dependent upon each other. To understand usage and benefits of technology in society, it is better to start with the combination of technology and integrated methods for studying aging and technology. This combined approach can give the base for upcoming changes in the form of technology and "good life" in older citizens. The question arises in the analysis of technological advancement as a social process that which technologies are developed, who considered it develop for whom and under what conditions (Hackett et al., 2007). 
These core aptitudes can be referred here, as they are focusing upon a dignified human life and fine super class society which is universal but culturally sensitive and therefore, acceptable. The list which is considered open is helpful in measuring and evaluating the technologies and their use to ensure a good life. It shows that the devised capabilities are operational, rather than asking technical questions around the technologies, we must dwell our attention towards the role of these technologies in developing core capabilities of humans. Our focus must not be upon the function of certain technologies rather reinstating or recompensing the deteriorating physical, mental or communicative abilities of a human being. Also not to see whether technological advances can increase the social participation of a person through mobility or has great positive impacts upon the lives of people ensuring quality. The development of human core aptitudes must be brought into light (Beimborn et al., 2016).

Certain societal and cultural conditions are to be considered through this approach as they temperate capabilities. For instance, let's take the bodily veracity being influenced by religious contemplations, cultural observance and societal discourse. To evaluate technologies, their expansion and usage, few of the dimensions must be operationalized like, is bodily integrity facilitated by the usage of a technology? Does it ensure social affiliation or disable attachments e.g. good bond of heed? Does technology improve lives of older people and increase older user's pragmatic reason? Does it allow them to emulate their situation? Does it let them expand an idea or plan of their own life? Does a user take power over his/her surroundings through technology? Does it make play possible? (Beimborn et al., 2016).

It is very complex and difficult to answer the aforementioned questions. Careful consideration is demanded, as the practical usage of technologies depends on social, cultural and institutional contexts. It does not only depend on cultural apposition. Principles to define the immobilizing or facilitating potentials of technologies rely on close collaboration with pragmatic social sciences. Ethnographic and qualitative advancements for the research of concrete interactions together of humans and technologies seem to be most prospective (Beimborn et al., 2016).

The context, in which the smart phones are used, is more rigorous and unpredictable than PC computer (Tamminen, Oulasvirta, Toiskallio, \& Kann akainen, 2004). Context, defined as the "circumstances and conditions that surround a place, thing, or event" (Moll, 2007) is one of the most important factor related to the smart phone usage. The user mostly interacts with one hand while using smartphone, which is cognitively a difficult environment, such as use of smartphone while walking and paying continuous attention to surroundings at the same time. Multitasking, in turn, decreased attention from resources available with smart phones. Smart phone users concentrate on giving full attention to monitor the surrounding for landmarks and checking whether they are going on right direction or not towards their destination (Tamminen et al., 2004). However, the challenges with environment while using smartphone is not exceptional for older people, but at the same time they also face a number of adoption challenges, unique to their age bracket, and face unique difficulties when interacting with technology due to age-related declines in physical, perceptual, and cognitive abilities, which may further discourage adoption of smart phones (Anderson \& Perrin, 2017). Moreover, psychological factors such as anxiety have been proposed to be related to adoption rates as well (Hernandez-Encuentra et al., 2009).

Despite recent increases in ownership, Anderson, and Perrin (2017, p. 1-22) found that most American adults over the age of 65 do not feel confident using their devices. Only $26 \%$ of Internet users, aged 65 years or older, reported, "feeling very confident when using computers, smart phones or other electronic devices to do the things they need to do online." Furthermore, 34\% reported feeling little to no confidence in using electronic devices like smart phones and computers to accomplish tasks online. Similarly, the survey asked respondents to rate how well they related to the phrase "When I get a new electronic device I usually need someone else to set it up or show me how to use it." Older adults aged 65 and older disproportionately rated themselves higher, with $73 \%$ saying it describes them very well or somewhat well. Notably, $62 \%$ of adults between the ages of 50 and 64 also stated that this describes them very well or somewhat well. This finding is supported by the finding that having regular support is one of the most important predictive factors of whether or not older adults will effectively integrate new technologies into their lives (Hernandez-Encuentra, Pousada \& Gomez-Zuniga, 2009, p. 235). 
Moreover, Kelley and Charness (1995) also found that older adults tended to require more support and time to learn new software. Perhaps, it is not surprising then, that of those aged 65 and over who did not report owning smart phones, 65\% report owning feature phones (Anderson \& Perrin, 2017). Another Pew Research survey of 2254 American adults, including 290 adults between the ages of 50 and 64 and 212 adults over the age of 65 , found that adults 50 and above reported feeling uniquely strong about not needing or desiring to upgrade to a smart phone (Smith, 2012). This study reported that the top three reasons adults 50 and over, with feature phones, do not upgrade to smart phones are: (Strausbaugh, 2001) an upgrade to a smart phone does not present sufficient benefits over a feature phone, (Kinsella \& Phillips, 2005) smart phones are too expensive and (World Health Organization, 2009) too complex or too difficult to use.

\section{METHODOLOGY}

The research design followed the qualitative research design for the current study. The researchers used the descriptive approach to understand the engagement patterns of senior citizens with smart phone. The qualitative methods were more suitable for the current issue because the researchers were trying to understand the subjective experiences of engagement. The quantitative method was not possible for collecting the detailed information through questionnaire. Therefore, the researchers used the interview guide in order to collect the in-depth information about the patterns of engagement. The research design further guided the researcher to investigate the respondent.

The researchers selected the city of Islamabad to understand the engagement practices of senior citizens with smart phone, as it is the developed region and people across the country with diverse ethnicity, culture and educational background migrate here for better living, greater job opportunities, and better education and health facilities. Further, there is a huge diversity in this region. People from diverse cultures and classes are living here because of the socio economic opportunities in the area. The target population in this region is significantly high as compared to other regions of Pakistan. Therefore, the researchers selected this area for his research.

The unit of analysis for this study was the population with age 50 years and above having smart phone. The unit of analysis encompasses both genders. Furthermore, this age group remained marginalized in the field of research and academia, that is why the researchers focused this age group. The sampling technique for this study was purposive sampling to collect the in-depth information. Moreover, the research question and objectives of the study suit the non-random purposive sampling. According to (Neuman, 2007), in purposive sampling, the researchers select those cases which are fit to their objective and research question. However, in the current study, the researchers selected those senior citizens who have smart phones and having the experiences of smart phone in their daily life. Therefore, the purposive sampling was more suitable for the current study.

Qualitative analysis generally required a small sample size than quantitative analysis. The goals of the qualitative research need to be the attainment of saturation. Saturation happens when adding more respondents to the research does not bring extra perceptions or material (Glaser \& Strass, 1967). The researchers collected data from 15 senior citizens who have the smart phones. Three out of these 15 respondents were female. The access to female respondents was hard due to socio cultural barriers. Furthermore, the researchers reached to the saturation point in the collected data, therefore the researchers decided to take this sample size enough for the information about the practices of engagements.

The researchers used interview guide for data collection from the target population. In the process of data collection, the researchers used face to face interview techniques in order to dig out the maximum information about the phenomenon, and to note and observe actions, attitudes and gestures of the respondents about the questions. With the permission of the respondents, the researchers recoded all the information. MAXQDA software was used for coding, generating themes and for analysis. The researchers used this scientific method in order to present the collected data in graphical form. 


\section{RESULTS AND DISCUSSION \\ Previous exposure to technology}

The main motive for the senior citizens in the use of technology is the core interest in technical devices. Engagement with technology has as high a need in their lives as was in their previous work experience. Many studies are supporting the hypothesis that the engagement in technology is a trade for their previous job (Pelizäus-Hoffmeister, 2016). In the current study, it is found that owing to their previous or current job, some of the participants were previously exposed to different technologies like computer, photocopier, fax and print machine. So the current data reflects that their motivation was due to their exposure to technology, and their educational background motivated them to use technology especially the smartphone. In the current study, there are some participants who were using the technology especially the mobile phone/smart phone from the very beginning which determines that their education and previous use of technology motivated them to use smart phone. stated that:

One of the respondents aged 54 years, who was a librarian, having double masters and MBA,

I am a librarian and I am used to different technologies because of my job. I have attained some training in technology. I am one of the early users of computer. I am using mobile phone since 1998 and I am using smart phone since it has launched. My desktop work is now shifted to my phone as it has replaced computer.

In addition, there was another participant, aged 67 and retired, responded in this regard:

I was at the position of manager in a private company in Dubai. I used computer and many other technologies at that time. My company gave me the mobile phone in 1994. My company also gave me laptop at that time.

Furthermore, another respondent, aged 55, currently working as a librarian and having double masters, argued that:

I think I am one of the early users of technology because of my job. I was using computer, print machine and fax very early due to my job. I attended some training on technology. I am using the smartphone since 2007-08 and used lab too.

It reflects from the above results that the previous engagement with different technologies and education background motivated the senior citizens to use the smart phones. The above data determined that the previous use and engagement with technology is one of the motivations for using the smartphone particularly in old age. Similarly, the results could be related to the study of Pelizäus-Hoffmeister (2016, p. 38-39) that the education background and previous use of technology affect the motivation of senior citizens for using smartphone.

\section{Social Connectedness}

It is the source of permanent access to other people. So it is very clear that the need of permanent and close integration with social circle of the senior citizens is another motive for using technology particularly the smartphone. The senior citizens always want to keep themselves informed from their children, friends and family. They are pleased that the new technology especially the social media allow them to be in touch with others easily, which was not that much easy in early times. However, they are not regularly in contact, but there is always the availability of others and the chance to connect them any time (Pelizäus-Hoffmeister, 2016). In the current study, some of the results determine that it satisfied the social need of individuals and senior citizens in particular. The smartphone, social media, WhatsApp and email program have the significant roles in the daily lives of the senior citizens. Furthermore, some of the features of smartphone have been identified as a source of extending and strengthening their social circle and therefore, smartphone is considered as a companion for senior citizens and become part of their lives. In this regards, one female respondent, aged 59, stated that:

I am receiving more video calls on WhatsApp because of my daughters who are abroad and I have specially bought this phone just because of them. Even I enjoy the birthdays of my grandsons and daughters through live video calls, which was impossible at early 
times. For parents, where ever their kids are, they can easily contact their kids and can get to know about them any time.

In addition, another respondent, aged 54, performing his duty as a librarian, stated that:

I use social networking like WhatsApp, LinkedIn and Facebook. On WhatsApp, I am part

of groups related to different tasks and some groups of friends and family.

Similarly, one of the respondents stated that:

Now this is a main source of information and has become important player in our lives without which we cannot imagine life. Now without mobile it feels like you have lost a part of your life. Once I was in Karachi, sitting in my car, and people knocked at my door and took my mobile on gunpoint. Till I didn't get new mobile, my blood pressure used to shoot.

Likewise, another respondent stated in this regard:

When you do not have a smart phone, it means you have nothing. My smartphone is my good friend.

In addition, one respondent argued that:

It is really difficult to stay without it

The above results indicated that there is a strong bond of companionship and attachment between the individuals and smartphones. The data also reflect the satisfaction of individual's social needs and their social attachment with smartphones. Moreover, the results determined that the senior citizens have been found more attached and satisfied with the use of smartphone.

\section{Smartphone and isolation}

The term isolation means the feeling of loneliness. Every individual in their lives face the feelings of loneliness, but in older age such feelings get more acute. Senior citizens' daily activities become very limited due to older age and its related issues. Their peer groups and sources of their engagement in term of entertainment and other activities to overcome such situation become limited. In such situation, the smartphone remains the only source of facilitation for senior citizens to overcome the isolation and engaged themselves through music, dramas, comedy, news, food recipes, sports, games and listening Quran etc. In the current data, some of the respondents responded:

I am alone almost every time so I use it then. Watching animal planet use to kill the time.

I am a house wife and most of the time I am alone at my home, using YouTube like watching my favorite dramas of Hum TV.

At my free time when I am getting bored, I use my smartphone for listing Ghazal.

Similarly, one the respondents, who uses it in his free time when getting bored, stated that:

I Just play cards game. I am doing it online with my 2 or 3 friends when we sit together and play it for approximately two to three hours.

However, few of the respondents facilitated their self via smartphone by reciting the Holy Quran and reading the hadiths to overcome their isolation. As few of them stated that:

In my free time, I mainly use it for reciting holy Quran.

Whenever I have free time and nothing to do, I use it for reciting holy Quran.

I am retired person, almost all the time I am alone. So mostly I am listening to Quran and I have collection of hadiths to read. 
The aforementioned data and subsequent results indicated that most of the respondents alleviated their isolation and utilized their free time by using smartphones for different activities such as watching dramas, listening music, playing games, listening to Quran and reading hadiths. It shows that the smartphones have facilitated the individuals especially the senior citizens to overcome their isolation through different means.

\section{Lack of Knowledge}

Knowledge plays an important role in operating any technology specifically the smartphone. Lack of knowledge creates difficulties in operating smartphones and becomes a barrier for the users particularly for senior citizens. Furthermore, in the current data, the lack of knowledge is found as barrier for the smartphone users, due to which they consider themselves the learners and take help from others whenever they need. As some of the respondents stated that:

\section{I do not know how to use data or connect it. My younger daughter helps me.}

I have very limited knowledge of smartphones and its applications; therefore, I often get help from my son and nephew.

Not that much but slowly and gradually, I am doing and taking help from my friends.

I do not have enough knowledge of smartphones and usually ask for my son's help.

I am just an average user and do not know about much things.

The data determined that majority of the respondents responded with "No" about the knowledge of the smartphones and internet. Besides this, some of the respondents stated that they have a limited knowledge and mostly ask for help form others. Similarly, one respondent had average knowledge of smartphone. The data, collected in this study, indicates that there is lack of knowledge among senior citizens regarding smartphones but it also reflects the interest of senior citizens in mobile technology as they often ask for help to learn about smartphone usage.

\section{CONCLUSION}

The results revealed about the active practices of senior citizens regarding smartphone usage, which revealed that the educational background and age differences have strong relation with the active use of smartphone among senior citizens. It has been found in the data that those elderly people, aged 50-60, who are highly educated have more active smartphone practices, while those who are less educated and in the age between 60 to 70 have been found with less active practices. This finding could be related to the literature in which the Berenguer et al. (2016) stated that the age difference has great impact on the use of technology particularly the smartphone. The literature indicates that the individuals in the young age or near to the old age have the ability of adaptation and good picking power to understand and learn the use of technology specially the smartphone. Similarly, another study related to this stated that the individuals who have good education background consider themselves modern, mentally flexible and open-minded, and have the ability to understand the use of smartphone because of their education (PelizäusHoffmeister, 2016).

Furthermore, the current study concluded the intended functions of different practices on smartphones, in which the results indicated that the intended function of using smartphone by senior citizens are communication and entertainment. In the current study, most of the individuals were found using smartphone for the purpose of communication and entertainment. The individuals have been found with the new easy and economical communication means like video calls and voice messages. Similarly, they also entertain their self with dramas, movies, videos, comedy, sports and games through their 
smartphones. Based on this finding, the related literature stated that in the United States, majority of the 50+ years individuals use their smartphones for calls, messages and internet for communication (Jenkins \& Parker, 2016). Furthermore, another study shows that in Japan, majority of the senior citizens with age $55+$ years use their smartphone for music, videos and for entertainment (Berenguer et al., 2016).

While some of the participants stated that they are also engaged with smartphone for using LinkedIn, Twitter, Instagram and other different applications of games, mobility, online banking, and websites for reading books and articles. Moreover, these practices of engagement indicated that they brought changes in their lives in term of more communication, more information, and more entertainment and have replaced laptop and desk top for small tasks. Furthermore, the study also highlighted some facilitation provided to senior citizens by smartphones. Most of the respondents described the facilitation of smartphones in term of more connectedness, more entertainment and more information. While some the respondents described the facilitation in terms of their convenience and online applications for mobility, online banking and online booking of different actives. Furthermore, in current study, the experiences of females have not been included on equal basis as that of males due to the socio cultural barriers. A future study could explore the experiences of old age females with technology in particular to smartphone. Similarly, it is important to conduct the quantitative study on the uses of smartphones in old age and the perception of senior citizens about smartphone. Such areas need to be addressed and further investigated in future studies.

\section{REFERENCES}

Anderson, M., \& Perrin, A. (2017). Technology use among seniors. Washington, DC: Pew Research Center for Internet \& Technology.

Beimborn, M., Kadi, S., Köberer, N., Mühleck, M., \& Spindler, M. (2016). Focusing on the human: Interdisciplinary reflections on ageing and technology. In Ageing and Technology: Perspectives from the Social Sciences. Transcript Verlag.

Berenguer, A., Goncalves, J., Hosio, S., Ferreira, D., Anagnostopoulos, T., \& Kostakos, V. (2016). Are smartphones ubiquitous?: An in-depth survey of smartphone adoption by seniors. IEEE Consumer Electronics Magazine, 6(1), 104-110.

Downey, G.L. (2001). Science and Technology, Anthropology of. Fernández-Ardèvol, M., \& Prieto, L. A. (2012). Mobile telephony and older people: Exploring use and rejection. Interactions: Studies in Communication \& Culture, 3(1), 9-24.

Dyk, S.V. (2009). Young old man in the field of tension of liberal activation, ageism and anti-aging strategies. J Aging Stud, 31, 93-103.

Glaser, B., Bailyn, L., Fernandez, W., Holton, J.A., \& Levina, N. (2013). What Grounded Theory Is? Academy of Management Proceedings, 1 .

Graebner, W. (1980). A history of retirement. Yale University Press.

Hackett, E., Amsterdamska, O., Lynch, M., \& Wajcman, J. (2007). New handbook of science, technology, and society. Cambridge, MA.

Hernández-Encuentra, E., Pousada, M., \& Gómez-Zúñiga, B. (2009). ICT and older people: Beyond usability. Educational Gerontology, 35(3), 226-245.

International data base. (2004). International program center, population division, US, bureau of census.

Jenkins, P. (2016). OMG-Not Something to LOL about: The Unintended Results of Disallowing Warrantless Searches of Cell Phones Incident to a Lawful Arrest. BYU J. Pub. L., 31, 437.

Kelley, C.L., \& Charness, N. (1995). Issues in training older adults to use computers. Behaviour \& Information Technology, 14(2), 107-120.

Kinsella, K.G., \& Phillips, D.R. (2005). Global aging: The challenge of success. Population Bulletin, 60(1).

Laslett, P. (1995). Necessary Knowledge: Age and Aging. Aging in the past. Demography, society, and old age, 7(3).

Moll, C. (2007). Mobile web design (Lulu. com).

Neuman, W.L. (2007). Social Research Methods: Quantitative and Qualitative Approaches. Pearson. 
Pelizäus-Hoffmeister, H. (2016). Motives of the Elderly for the Use of Technology in their Daily Lives. In Aging and technology. Transcript publishing house.

Smith, A. (2012). The best (and worst) of mobile connectivity. Washington, DC: Pew Internet \& American Life Project.

Strausbaugh, L.J. (2001). Emerging health care-associated infections in the geriatric population. Emerging infectious diseases, 7(2), 268.

Tamminen, S., Oulasvirta, A., Toiskallio, K., \& Kankainen, A. (2004). Understanding mobile contexts. Personal and ubiquitous computing, 8(2), 135-143.

Thane, P. (2005). The twentieth century. In P. Thane (Ed.), A history of old age London. Thames and Hudson.

Tongren, H.N. (1988). Determinant behavior characteristics of older consumers. Journal of Consumer Affairs, 22(1), 136-157.

United Nations Organization. (2002). World Population Ageing 1950-2050. New York: Economic and Social Affairs, Population Division.

United Nations. (2004). World Population to 2300. New York: 2004 world population perspective: the 2006 Revision. Network United Nation.

World Health Organization. (2007). Definition of an older or elderly person. Retrieved from http://www.who.int/healthinfo/survey/ageingdefnolder/en/print.html

World Health Organization. (2009). Ageing - Exploding the Myths. Geneva: Ageing and Health Programme (AHE).

Retrieved

from:

(http://whqlibdoc.who.int/hq/1999/WHO_HSC_AHE_99.1.pdf) 